\title{
Cognitive Decline and Hearing Health Care for Older Adults
}

\author{
Kathleen M. Pichora-Fuller
}

\section{Linköping University Post Print}

\section{Tweet}

N.B.: When citing this work, cite the original article.

Original Publication:

Kathleen M. Pichora-Fuller, Cognitive Decline and Hearing Health Care for Older Adults, 2015, American Journal of Audiology, (24), 2, 108-111.

http://dx.doi.org/10.1044/2015_AJA-14-0076

Copyright: American Speech-Language-Hearing Association http://www.asha.org/default.htm

Postprint available at: Linköping University Electronic Press

http://urn.kb.se/resolve?urn=urn:nbn:se:liu:diva-120658 
Cognitive decline and hearing health care for older adults

\author{
M. Kathleen Pichora-Fuller \\ Department of Psychology, University of Toronto, Canada \\ Linneaus Centre HEAD, Linköping University, Sweden
}

Contact information:

M. Kathleen Pichora-Fuller, Department of Psychology, University of Toronto, 3359 Mississauga Rd.

Mississauga, Ontario

Canada L5L 1 C6

Phone: 905-828-3865

Fax: 905-569-4326

Email: k.pichora.fuller@utoronto.ca

Acknowledgment: The forum on "The Challenges in Hearing Health Care for the Oldest Older Adults" (Forum Coordinator: Judy Dubno) took place at the HEAL (HEaring Across the Lifespan) conference on "Early intervention: the key to better hearing care", Lake Como, Italy, June 5, 2014. 


\begin{abstract}
Purpose

The purpose of this paper is to consider the implications of age-related cognitive decline for hearing health care.

Method

Recent research and current thinking about age-related declines in cognition and the links between auditory and cognitive aging were reviewed briefly. Implications of this research for improving prevention, assessment and intervention in audiologic practice and for enhancing inter-professional teamwork were highlighted.

Conclusion

Given the important connection between auditory and cognitive aging, and given the high prevalence of both hearing and cognitive impairments in the oldest older adults, health care services could be improved by taking into account how both the ear and the brain change over the lifespan. By incorporating cognitive factors into audiologic prevention, assessment and intervention, hearing health care can contribute to better hearing and communication, as well as to healthy aging.
\end{abstract}

Keywords:

Cognitive aging, mild cognitive impairment, dementia, age-related hearing loss, audiologic rehabilitation 
The everyday functioning of older communicators with hearing loss may affect and be affected by co-occurring health conditions. Arguably, cognitive decline is the co-morbidity that looms largest in the minds of patients, audiologists, and policy makers. Conversely, hearing loss is now of increasing interest to neuropsychologists, primary care physicians, geriatricians, nurses, and other health professionals whose usual focus is on cognitive loss. The quality of life and the quality of health care could be improved for many older adults by taking into account the connections between age-related declines in hearing and cognition and enhancing inter-professional teamwork. This paper explores the need for new approaches to prevention, assessment and intervention strategies for older adults with hearing loss who are at risk for or who already have dementia.

Age-related cognitive declines and hearing loss

Over the adult lifespan, there are gradual and age-related losses in cognitive processing (e.g. speed of information processing and some types of memory and attention), but gains in cognitive knowledge (e.g. vocabulary, world knowledge, expertise) (Park et al., 2002). Importantly, age-related cognitive gains can be used to compensate for cognitive losses in healthy older adults (Craik \& Bialystok, 2008), with associated changes in patterns of brain activation (Grady, 2012). Beyond normal age-related cognitive changes, clinically significant mild cognitive impairment (MCI) and dementia increase with age, with about a fifth of people having a clinically significant cognitive loss by the age of 70 years (Yesavage et al. 2002). The prevalence of dementia increases from $5 \%$ of those aged $71-79$ years to 
$37 \%$ of those aged 90 and older, with an overall prevalence of approximately $14 \%$ for those over 70 years of age (Plassman et al., 2007). Recently refined diagnostic criteria for MCI and dementia (Albert et al., 2011; McKhann et al., 2011) recognize that there is a continuum, with MCI being an intermediary stage that often, but not always, progresses to Alzheimer's disease (AD). The rate of conversion from MCI to $\mathrm{AD}$ is about $10-15 \%$ per year, with about an $80 \%$ conversion rate after 6 years (Petersen et al., 2001), a rate much higher than the rates of only 1 to $2 \%$ per year for the general population (Petersen et al., 1999). AD is the most common form of dementia; it is a progressive and degenerative brain disease that is typically fatal within 10 years of diagnosis for those diagnosed by their early 70s (Brookmeyer et al., 2002).

Hearing loss also increases gradually with age; about a third have a clinically significant loss by the age of 65 years, about half by 75 years, and most by 80 years (Yueh et al., 2003). Given the high prevalence of hearing loss in older adults, and given that both hearing loss and cognitive loss increase in prevalence with age, it is reasonable to assume that cognitive problems are common in most of the oldest older adults who have hearing loss. In fact, dementia is more prevalent in people with hearing loss than in counterparts without hearing loss (Uhlman et al., 1986, 1989). Strikingly, epidemiologic research indicates that scores on tests of auditory central processing (Gates et al., 2002, 2010, 2011), and even audiometric thresholds (Lin et al., 2011a,b, 2013), are associated with incident dementia. Individuals with hearing loss have a 2 to 5 times increased risk of developing dementia compared to peers with normal hearing (Lin et al., 2011a). With every $10 \mathrm{~dB}$ increase in hearing 
loss over $25 \mathrm{~dB}$ HL, there is a $20 \%$ increased risk of developing dementia (Lin et al., 2011b). In adults over 65 years old, the mean time to develop dementia was 10.3 years in those with hearing loss at baseline versus 11.9 years for counterparts with normal hearing (Gurgel et al., 2014).

Prevention

In light of the connection between age-related auditory and cognitive declines, questions are raised as to what the mechanisms underlying the connection might be and if earlier or better hearing health care could stave off or slow down dementia (Lin et al., 2013; Pichora-Fuller, 2010). The popular 'use it or lose it' view of cognitive aging has been supported by evidence that a range of lifestyle factors involving social, physical or mental activity can help to protect older adults from cognitive decline (e.g., Scarmeas et al., 2003), including engagement in social leisure activities (e.g., Fratiglioni, 2004), physical exercise and/or eating a Mediterraneantype diet (e.g., Scarmeas et al., 2009), or cognitive expertise such as being bilingual (e.g., Bialystok, Craik, \& Freedman, 2007) or a musician (e.g., Hanna-Pladdy, \& MacKay, 2011). One possibility is that the relationship between hearing loss and incident dementia is mediated by lifestyle factors; e.g., participation in social leisure activities is known to be related to good cognition but is compromised by hearing loss. Since AD has become a dominant global public health concern, rigorous research is needed to investigate the possibility that hearing rehabilitation could help to stave off or slow it down, for example, by preventing social withdrawal. 


\section{Assessment}

Two questions of great practical importance concern are 1) to what extent do hearing loss and/or noisy test environments undermine the accuracy of cognitive assessments? and 2) could audiologic practice be improved by taking cognition into account when assessing client needs? It seems that inter-professional teamwork could help audiologists, neuropsychologists, physicians and other health professionals to better understand the differential and combined effects of hearing loss and cognitive loss on task performance in the clinic and on functioning in everyday life.

As the population ages, more health professionals are administering cognitive screening tests more often to more patients in a wider range of settings. Most physicians administer cognitive screening tests when diagnosing dementia (Davey \& Jamieson, 2004), but only a minority even ask about hearing (Jorgensen, Palmer \& Fischer, 2014). Because cognitive tests often require the patient to hear instructions and respond to auditory stimuli, unless these tests are administered in a quiet environment using appropriate listening technology, cognitive abilities may be underestimated. Audiologists could help by providing information about the hearing abilities and needs of those who are undergoing cognitive testing so that the influence of hearing loss and/or noise on the results can be controlled and appropriately interpreted. Nevertheless, even when testing conditions are optimized and hearing loss is taken into account during testing, it still seems that those with hearing loss do not perform as well on cognitive screening tests as peers with good hearing (Dupuis et al. 2014). These findings suggest that health care 
professionals concerned with cognitive health may need to monitor older adults in the early stages of cognitive decline more aggressively if they have hearing loss than if they have good hearing. At the same time, audiologists may need to offer audiologic interventions tailored to the needs of these patients and/or to collaborate in inter-professional teams providing interventions to bolster cognitive health or to support caregivers of people with dementia (Pichora-Fuller et al., 2013).

\section{Intervention}

Other questions awaiting answers concern how to tailor interventions to the ongoing needs of those with dual hearing and cognitive losses and their caregivers. Rather than waiting until MCI or AD has been identified, earlier intervention using a health promotion approach to encourage help-seeking for hearing loss may be advantageous. Some evidence suggests that hearing rehabilitation could contribute to cognitive health (Allen et al., 2003). For those already diagnosed with dementia, hearing aid use can reduce the number of problem behaviors reported by caregivers (Palmer et al., 1998, 1999).

Surprisingly little is known about audiologic best practice for treating the oldest older adults who have dual hearing and cognitive impairments (PichoraFuller et al., 2013). Too often, the oldest older adults do not have access to hearing care because audiological services are typically delivered in clinics or offices rather than in a home care or community care service delivery model. Another reason that geriatric audiology services may not be provided is the belief by some that the

oldest older adults cannot learn to use hearing aids. Fortunately, a combination of 
factors now set the stage for new approaches to delivering hearing health care to the oldest older adults. These factors include new knowledge about cognitive aging and brain plasticity, changing attitudes about aging and disability, and the urgent social imperative to meet the health care needs of the growing number of people who are eager to age successfully and preserve their health. Other papers in this forum provide examples of such new approaches.

Future research

Much future research is needed! For prevention, well-controlled, longitudinal clinical trials are needed to provide strong evidence that hearing rehabilitation could stave off or slow down dementia. For assessment, research is needed about how best to advance inter-professional teamwork so that information about hearing can guide cognitive health care and information about cognition can guide hearing health care. For intervention, research is needed to characterize how hearing loss influences caregiver burden, with related program development and evaluation research to demonstrate the benefits of intervention in reducing caregiver burden for family members of the oldest old who have both hearing loss and dementia. 


\section{Acknowledgment}

This paper was presented in the Forum on "The Challenges in Hearing Health Care for the Oldest Older Adults" (Forum Coordinator: Judy Dubno) at the HEAL (HEaring Across the Lifespan) conference on "Early intervention: the key to better hearing care", Lake Como, Italy, June 5, 2014. 


\section{References}

Albert, M.S., DeKosky, S.T., Dickson, D., Dubois, B., Feldman, H.H., Fox, N.C., ... Phelps, C.H. (2011). The diagnosis of mild cognitive impairment due to Alzheimer's disease: Recommendations from the National Institute on Aging and Alzheimer's Association workgroup. Alzheimer's and Dementia, 7, 270-279.

doi:10.1016/j.jalz.2011.03.008

Allen, N.H., Burns, A., Newton, V., Hickson, F., Ramsden, R., Rogers, J., ... Morris, J. (2003). The effects of improving hearing in dementia. Age and Ageing, 32, 189-193. doi: 10.1093/ageing/32.2.189

Bialystok, E., Craik, F. I. M., \& Freedman, M. (2007). Bilingualism as a protection against the onset of symptoms of dementia. Neuropsychologia, 45, 459464. doi:10.1016/j.neuropsychologia.2006.10.009

Brookmeyer, R., Corrada, M., Curriero, F., \& Kawas, C. (2002). Survival following a diagnosis of Alzheimer disease. Archives of Neurology, 59, 1764-1767. doi:10.1001/archneur.59.11.1764

Craik F.I.M. \& Bialystok E. (2008). Lifespan cognitive development: The roles of representation and control (pp. 557-601). In F. Craik \& T. Salthouse, (Eds). Handbook of aging and cognition (3 $3^{\text {rd }}$ ed.). New York, NY: Psychology Press.

Davey, R.J., \& Jamieson, S. (2004). The validity of using the mini mental state examination in NICE dementia guidelines. Journal of Neurology, Neurosurgery and Psychiatry, 75, 341-345. doi:10.1136/jnnp.2003.016063

Dupuis, K., Pichora-Fuller, M.K., Chasteen, A., Marchuk, V., Smith, S.L., \& Singh, G. (2014). Effects of hearing and vision impairments on the Montreal Cognitive 
Assessment. Aging, Neuropsychology and Cognition._Oct 17:1-25. [Epub ahead of print]. PMID 24325767; DOI: 10.1080/13825585.2014.968084

Fratiglioni, L., Paillard-Borg, S., \& Winblad, B. (2004). An active and socially integrated lifestyle in late life might protect against dementia. Lancet Neurology, 3, 343-53. http://dx.doi.org/10.1016/S1474-4422(04)00767-7

Gates, G.A., Anderson, M.L., McCurry, S.M., Feeney, M.P., \& Larson, E.B. (2011). Central auditory dysfunction is a harbinger of Alzheimer's dementia. Archives of Otolaryngology -- Head and Neck Surgery, 137, 390-395.

doi: 10.1001/archoto.2011.28

Gates, G.A., Beiser, A., Rees, T.S., D’Agostino, R.B., \& Wolf, P.A. (2002). Central auditory dysfunction may precede the onset of clinical dementia in people with probable Alzheimer's disease. Journal of the American Geriatrics Society, 50, 482488. DOI: 10.1046/j.1532-5415.2002.50114.x

Gates, G.A., Gibbons, L.E., McCurry, S.M., Crane, P.K., Feeney, M.P., \& Larson, E.B. (2010). Executive dysfunction and presbycusis in older persons with and without memory loss and dementia. Cognitive and Behavorial Neurology, 23, 218-223. doi: 10.1097/WNN.0b013e3181d748d7

Grady, C. (2012). The cognitive neuroscience of ageing. Nature Reviews Neuroscience, 13, 491-505. doi: 10.1038/nrn3256.

Gurgel, R.K., Ward, P.D., Schwartz, S., Norton, M.C., Foster, N.L., \& Tshanz, J.T. (2014). Relationship of hearing loss and dementia: a prospective, population-based study. Otology and Neurotology, 35, 755-781. doi:

10.1097/MA0.0000000000000313 
Hanna-Pladdy, B., \& MacKay, A. (2011). The relation between instrumental musical activity and cognitive aging. Neuropsychology, 25, 378-386. doi: $10.1037 / \mathrm{a} 0021895$.

Jorgensen, L., Palmer, C., \& Fischer, G. (2014). Evaluation of hearing status at the time of dementia diagnosis. Audiology Today, 26, 38-45.

Lin, F.R., Ferrucci, L., Metter, E.J., An, Y., Zonderman, A.B., \& Resnick, S.M. (2011a) Hearing loss and cognition in the Baltimore Longitudinal Study of Aging. Neuropsychology, 25, 763-770. http://dx.doi.org/10.1037/a0024238

Lin, F.R., Metter, E.J., O’Brien, R.J., Resnick, S.M., Zonderman, A., \& Ferrucci, L. (2011b). Hearing loss and incident dementia. Archives of Neurology, 68, 214-220. doi:10.1001/archneurol.2010.362.

Lin, F.R., Yaffe, K., Xia, J., Xue, Q.-L., Harris, T.B., Purchase-Helzner, E., ... Simonsick, E.. (2013). Hearing loss and cognitive decline in older adults. Journal of the American Medical Association: Internal Medicine, 173, 293-9.

doi:10.1001/jamainternmed.2013.1868

McKhann, G.M., Knopman, D.S., Chertkow, H., Hyman, B.T., Jack Jr, C.R., Kawas, C.H., .... Phelps, C.H. (2011). The diagnosis of dementia due to Alzheimer's disease: Recommendations from the National Institute on Aging-Alzheimer's Association workgroups on diagnostic guidelines for Alzheimer's disease. Alzheimer's and Dementia, 7, 263-269. http://dx.doi.org/10.1016/j.jalz.2011.03.005

Palmer, C.V., Adams, S.W., Bourgeois, M., Durrant, J., \& Rossi, M. (1999). Reduction in caregiver-identified problem behaviors in clients with Alzheimer 
disease post-hearing-aid fitting. Journal of Speech and Hearing Research, 42, 312328. http://dx.doi.org/10.1044/jslhr.4202.312

Palmer, C.V., Adams, S.W., Durrant, J., Bourgeois, M., \& Rossi, M. (1998). Managing hearing loss in a client with Alzheimer disease. Journal of the American Academy of Audiology, 9, 274-284.

Park, D.C., Lautenschlager, G., Hedden, T., Davidson, N.S., Smith, A.D., Smith, P.K. (2002). Models of visuospatial and verbal memory across the adult life span. Psychology and Aging, 17, 299-320. http://dx.doi.org/10.1037/0882-7974.17.2.299

Petersen, R.C., Doody, R., Kurz, A., Mohs, R.C., Morris, J.C., Rabins, P.V., ... Winblad, B. (2001). Current concepts in Mild Cognitive Impairment. Archives of Neurology, 58, 1983-1992. http://dx.doi.org/10.1001/archneur.58.12.1985

Petersen, R.C., Smith, G.E., Waring, S.C., Ivnik, R.J., Tangalos, E.G., \& Kokmen, E. (1999). Mild cognitive impairment: Clinical characterization and outcome. Archives of Neurology, 56, 303-308. http://dx.doi.org/10.1001/archneur.56.3.303

Pichora-Fuller, M.K. (2010). Using the brain when the ears are challenged helps healthy older listeners compensate and preserve communication function (pp. 53-65). In L. Hickson (Ed.). Hearing care for adults. Phonak: Stäfa, Switzerland.

Pichora-Fuller, M.K., Dupuis, K., Reed, M., \& Lemke-Kalis, U. (2013). Helping older people with cognitive decline communicate: Hearing aids as part of a broader rehabilitation approach. Seminars in Hearing, 34, 307-329.

Plassman, B.L., Langa, K.M., Fisher, G.G. Heeringa, S.G., Weir, D.R., Ofstedal, M.B., ... Wallace, R.B. (2007). Prevalence of dementia in the United States: The aging, 
demographics, and memory study. Neuro-epidemiology, 29, 125-132.

http://dx.doi.org/10.1159/000109998

Scarmeas, N., Luchsinger, J. A., Schupt, N., Brickman, A. M., Cosentino, S., Tang, M. X., \& Stern, Y. (2009). Physical activity, diet, and risk of Alzheimer Disease. Journal of the American Medical Association, 302, 627-637. http://dx.doi.org/10.1001/jama.2009.1144

Scarmeas, N., \& Stern, Y. (2003). Cognitive reserve and lifestyle. Journal of Clinical and Experimental Neuropsychology, 25, 625-633. http://dx.doi.org/10.1076/jcen.25.5.625.14576

Uhlmann, R.F., Larson, E.B., \& Koepsell, T.D. (1986). Hearing impairment and cognitive decline in senile dementia of the Alzheimer's type. Journal of the American Geriatrics Society, 34, 207-210.

Uhlmann, R.F., Larson, E.B., Rees, T.S., Koepsell, T.D., \& Duckert, L.G. (1989). Relationship of hearing impairment to dementia and cognitive dysfunction in older adults. Journal of the American Medical Association, 261, 1916-1919. http://dx.doi.org/10.1001/jama.1989.03420130084028

Yesavage, J.A., O’Hara, R., Kraemer, H., Noda, A., Taylor, J.L., Ferris, S., ... Derouesné, C. (2002). Modeling the prevalence and incidence of Alzheimer's disease and mild cognitive impairment. Journal of Psychiatric Research, 36, 281-286. http://dx.doi.org/10.1016/S0022-3956(02)00020-1

Yueh, B., Shapiro, N., MacLean, C.H., \& Shekelle, P.G. (2003). Screening and management of adult hearing loss in primary care: Scientific review. Journal of the 
American Medical Association, 289, 1976-1985.

http://dx.doi.org/10.1001/jama.289.15.1976 